\title{
Revista Brasileira de Enfermagem REBEn Relação tempo-violência no trabalho
de enfermagem em Emergência e Urgência
}

The relation between time and violence in the nursing work at Emergency and Urgency

Relación tiempo-violencia en el trabajo de enfermería en emergencia y urgencia

\section{Aldenan Lima Ribeiro Corrêa da Costa}

Doutora em Enfermagem Fundamental, Professora Adjunto do Departamento de Enfermagem da Faculdade de Enfermagem da Universidade Federal de Mato Grosso.

\section{Maria Helena Palucci Marziale}

Doutora em Saúde do Trabalhador. Professora Associada do Departamento de Enfermagem Geral e Especializada da Escola de Enfermagem de Ribeirão preto da Universidade de São Paulo.Centro Colaborador da OMS/OPS para o desenvolvimento de pesquisa em Enfermagem.

Texto extraído da Tese de Doutoramento intitulada: As múltiplas formas de violência no trabalho de enfermagem: o cotidiano de trabalho no setor de emergência e urgência clínica em um hospital público, apresentada ao Programa de Pós-Graduação em Enfermagem Fundamental da Escola de Enfermagem de Ribeirão Preto da Universidade de São Paulo EM Março/2005.

Submissão: 19/07/2005

Aprovação: 03/02/2006

\section{RESUMO}

Acreditando-se que a forma de organização e a quantidade de tempo destinada ao trabalho assistencial hospitalar podem se constituir em causa de violência que afeta a vida de trabalhadores e usuários analisou-se a percepção dos trabalhadores sobre o tempo disponibilizado às suas atividades e as manifestações de violência no contexto de trabalho de emergência e urgência de um hospital público de Mato Grosso. Trata-se de uma pesquisa qualitativa realizada junto aos membros da equipe de enfermagem, com dados coletados por meio de observação participante e entrevistas. Os dados analisados tematicamente revelaram que o tempo insuficiente de trabalho faz parte da gênese da violência no trabalho de enfermagem e se apresenta tipificada em violência: clássica, estrutural, repressiva e alienação.

Descritores: Violência; Enfermagem em emergência; Saúde ocupacional; Disciplina no trabalho, Tempo, lugar e pessoa.

\section{ABSTRACT}

Believing that the organization form of work and the quantity of time given to the assistance work in the hospital can become a cause of violence that affects workers' and usuaries' life, this article analyzed the workers' perception about the time they have for their activities and the violence demonstration in the context of emergency and urgency work of a public hospital of Mato Grosso. It's a qualitative research done close to the members of the nursing staff, with data collected through participative observation and interviews. The data thematically analyzed revealed that the insufficient time makes part of the violence genesis at the nursing work and it is characterized as: classical, structural, repressive and alienation violence.

Descriptors: Violence; Emergency Nursing; Occupational health; Employee discipline; Descriptive epidemiology.

\section{RESUMEN}

Creyéndose que la forma de organización y la cantidad de tiempo, destinada al trabajo asistencial hospitalario, pueden constituirse en causa de violencia que afecta la vida de trabajadores y usuarios, fue analizada la percepción de los trabajadores sobre el tiempo disponibilizado a sus actividades y a las manifestaciones de violencia en el contexto de trabajo de emergencia y urgencia de un hospital público de Mato Grosso. Trátase de una pesquisa cualitativa realizada junto a los miembros del equipo de enfermería, con datos colectados por medio de observación participante y encuestas. Los datos analizados temáticamente revelaron que el tiempo insuficiente de trabajo hace parte de la génesis de la violencia en el trabajo de enfermería y se presenta tipificada en violencia: clásica, estructural, represiva y alienación.

Descriptores: Violencia; Enfermería de urgencia; Salud ocupacional; Disciplina laboral, Epidemilogía descriptiva.

Costa ALRC, Marziale MHP. Relação tempo-violência no trabalho de enfermagem em Emergência e Urgência. Rev Bras Enferm 2006 maio-jun; 59(3):337-43.

\section{INTRODUÇÃO}

A violência no local de trabalho em qualquer de suas manifestações pode ter efeito devastador e de longa duração nas pessoas afetadas. De acordo com a Organização Internacional do Trabalho - OIT a origem da violência obedece a uma combinação de causas relacionadas às pessoas, contexto ambiental, condições de trabalho e à interação dos trabalhadores entre si e com os seus empregadores. Isto significa que a violência no local de trabalho não se relaciona apenas a fatores pessoais e comportamentais, mas também a fatores estruturais, inclusive da própria organização do trabalho(1).

Mesmo considerando que as organizações de trabalho deveriam cumprir um papel protetor, principalmente as instituições de saúde das quais se espera a proteção dos danos que ameaçam 
a vida humana, isso pode não ocorrer. Os hospitais não estão livres da presença da violência. Assim, faz-se necessário entender o mecanismo que transforma um ambiente terapêutico em um local de violência e degradação.

A violência se manifesta de diferentes formas e acomete diversos grupos de pessoas, razão pela qual se torna difícil sua apreensão e definição. Em 1996 uma resolução da Assembléia Mundial de Saúde declarou a violência como um problema de Saúde Pública global, conceituando-a como a utilização da força ou poder físicos de forma intencional seja por meio de ameaças ou de fato, de uma pessoa a si mesma ou de outra pessoa, contra um grupo ou comunidade, que tenha como conseqüência uma alta possibilidade de causar danos sociológicos, disfunções, privações ou morte(2).

$\mathrm{Na}$ violência física, a força é usada intencionalmente de modo que pode causar a morte ou ferimentos. Na violência sexual essa força é utilizada para forçar a pessoa a um ato sexual indesejado. A violência pode ser também psicológica e neste caso, um abuso verbal ocorre com o "objetivo de controlar outros indivíduos pela degradação, humilhação e medo"(3).

A violência psicológica pode assumir contornos devastadores quando se transforma em assédio moral, ou conduta abusiva, evidenciada por gestos, atitudes, comportamentos ou palavras de modo sistemáticos e repetidos atentando contra a "dignidade ou integridade psíquica ou física de uma pessoa, ameaçando seu emprego ou degradando o clima de trabalho"(4). Embora não visível, o assédio moral é um tipo de violência destrutiva, pois ocorre de forma repetitiva e não assinalável, comprometendo a auto-estima, auto-imagem, enfim, a integridade física e emocional da pessoa vitimada.

A violência é ainda considerada como uma violação dos direitos humanos, pois sendo eles, essenciais a todas as pessoas de uma sociedade, o seu desrespeito implica sempre em uma violência ${ }^{(5)}$.

Uma medida a ser tomada para a compreensão do fenômeno violência é negar a aceitação de sentenças abstratas e aceitá-la como um fenômeno ambíguo. Além disso, é preciso um adequado preparo para o seu enfrentamento de suas manifestações, questionando-a sobre as suas formas de ataque e buscando os métodos necessários para detê-la(6).

Faz-se necessário buscar fundamentos teóricos sobre a possivel relação existente entre o trabalho hospitalar e a violência. Qual é a origem da violência nas instituições hospitalares de saúde? Existe relação entre tempo disponível de trabalho e violência no cenário assistencial de emergência e urgência clínica?

Estes questionamentos evidenciaram a necessidade de um aprofundamento sobre a relação "trabalho versus tempo", com base no pressuposto de que dependendo da forma de organização do tempo de trabalho nas organizações de saúde, o tempo insuficiente pode se constituir em uma das causas de violência sobre a vida dos trabalhadores e dos seres sob seus cuidados. Desse modo, o objetivo desse estudo foi analisar a percepção do tempo disponivel para a realização das atividades assistenciais de enfermagem em um setor de emergência e urgência clínica e sua relação com as manifestações de violência nesse contexto de trabalho.

\section{REFERENCIAL TEÓRICO}

No Brasil a violência no trabalho vem desde o escravismo, onde era visualizada pela supressão da liberdade, da vontade e do poder de decisão do escravizado. Embora o sistema de assalariamento que sucedeu a escravidão, tenha priorizado estabelecimento de contrato entre indivíduos não escravos, sua introdução trouxe uma gestão e organização do trabalho escravo e suas formas de violências. Neste sistema, muda-se a forma de sujeição e o trabalhador passa a ser "escravo" do próprio trabalho(7).
Como uma expressão de violência no trabalho, no ano de 2002, as estatísticas brasileiras demonstraram a ocorrência de 387.905 acidentes de trabalho, dos quais 15.029 pessoas ficaram incapacitadas permanentemente e 2.898 morreram. Do total desses acidentes, $82,6 \%$ (320.398) corresponderam a acidentes típicos, ou seja, aqueles ocorridos decorrentes ao exercício do trabalho(8).

Sendo a violência um problema de Saúde Pública merece ser investigada em todos os contextos de atuação humana, principalmente no contexto do trabalho em saúde onde há necessidade de esclarecimentos sobre o fenômeno para oportunizar sua prevenção, enfrentamento e oferecer um atendimento adequado às pessoas que sofreram danos violentos. Neste sentido, faz-se necessário também, 0 entendimento das políticas públicas de saúde como espaço de resolução dos danos a saúde da população.

No Brasil, desde 1988 a saúde foi garantida como direito de todos e um dever do Estado pela Constituição Federal Brasileira, que estabeleceu acesso igualitário, universal e integral às ações de promoção, prevenção e recuperação da saúde à população brasileira, pelo Sistema Único de Saúde (SUS). As instituições privadas participam do sistema de forma complementar ${ }^{(9)}$.

$\mathrm{Na}$ busca do entendimento da possível relação entre tempo disponível de trabalho e violência no cenário assistencial de emergência e urgência clínica constatou-se na literatura que a importância do tempo no contexto do trabalho iniciou-se a partir da Revolução Industrial, havendo uma mudança significativa em sua compreensão e gradativamente foi se transformando a concepção do tempo de caráter cíclico, descontínuo e qualitativo com base no tempo natural das alternâncias do dia e da noite e das estações do ano ${ }^{(10)}$.

As bases para a relação tempo e trabalho foram determinadas no Ocidente. Uma dessas bases - a invenção do relógio e os seus conseqüentes aperfeiçoamentos - se tornou elemento importante na dominação tecnológica e econômica do ocidente em relação ao mundo, mesmo antes do processo de industrialização. Além disso, o entendimento de pensadores como Léon Battista Alberti e Benjamim Franklin forneceram elementos para a consideração do tempo como uma mercadoria, colaborando para o surgimento do espírito capitalista ${ }^{(11)}$. Assim, começa a se firmar especialmente nos países de tradição protestante, uma concepção de tempo como elemento central. A partir desse entendimento vai se desenvolvendo a relação entre tempo e trabalho que caracteriza as sociedades industrializadas ${ }^{(11)}$.

Um novo sistema produtivo e um novo meio social de produção surge com a industrialização: a fábrica. Nesta, novos espaços-tempos de trabalho são estabelecidos, ou seja, um novo espaço de atividade produtiva e um novo quadro temporal de trabalho, marcado pelo tempo do relógio, pelo ritmo das máquinas e jornada de trabalho, começaram a funcionar. Uma nova disciplina do trabalho foi instaurada, com exigência de pontualidade e regularidade, em oposição a anterior alternância entre períodos de intensas atividades de trabalho seguidos de períodos de inatividade para compensação do corpo. Agora, o corpo deve se ajustar ao novo sistema produtivo. Assim, a disciplina do tempo de trabalho imposta a partir da industrialização passou a constituir um instrumental básico no modo de produção capitalista ${ }^{(11)}$.

Sendo o tempo de trabalho um dos determinantes do salário operário, é, portanto, uma categoria fundamental no sistema capitalista. Além disso, a economia de tempo, em termos gerais, representa um elemento essencial na produção moderna, de modo que, economia e distribuição programada do tempo de trabalho é a primeira lei de economia básica da produção social(12).

As formas de produção de trabalho nas fábricas se expandiram e influenciaram todos os setores. Assim, o setor de serviços, embora com diferentes atividades e diversificados modos de produção, é também influenciado pela lógica capitalista, por suas formas de organização do 
trabalho e pela tecnologia(13).

O hospital, fazendo parte do setor de serviços sofre estas mesmas influências, sendo o tempo de trabalho um aspecto que merece ser estudado, principalmente quando se considera que o produto do trabalho em saúde é consumido conjuntamente com a sua produção. Deste modo, a organização do processo de trabalho em saúde, ao adotar o tempo linear e quantitativo na condução das atividades de saúde pode causar danos à integridade dos trabalhadores, o que pode ser caracterizado como uma forma de violência sobre o corpo dos trabalhadores e das pessoas assistidas no processo terapêutico.

A fundamentação teórica sobre a linearidade do tempo no modo de produção capitalista permite a consideração da vida cotidiana do trabalhador de enfermagem hospitalar, nesse modo de produzir a vida produzindo saúde. Assim, questiona-se: Qual é a percepção de trabalhadores sobre o tempo no contexto do trabalho de emergência e urgência? De que forma a utilização do tempo no trabalho se relaciona com a violência laboral?

\section{METODOLOGIA}

Estudo de natureza qualitativa, realizado no período de maio a outubro de 2003, em uma instituição hospitalar pública do Estado de Mato Grosso - Brasil, no setor de emergência e urgência clínica. Tratase de um dos problemas investigados em uma ampla pesquisa desenvolvida sobre a violência sofrida por trabalhadores de enfermagem e faz parte da Tese de Doutoramento: As múltiplas formas de violência no trabalho de enfermagem: o cotidiano de trabalho no setor de emergência e urgência clínica em um hospital público.

A pesquisa foi aprovada pelo Comitê de Ética de Mato Grosso e a coleta dos dados foi realizada por meio de entrevista, com dez enfermeiros, três técnicos e três auxiliares de enfermagem, e por observação participante. Após explicação sobre os objetivos e procedimentos metodológicos da pesquisa a cada participante, as entrevistas foram gravadas com o seu consentimento por escrito e digitadas em seguida. Para garantia do sigilo das pessoas envolvidas, foram utilizados nomes fictícios, extraídos da língua Tupy Guarani, na identificação de seus relatos.

As observações participantes foram realizadas pela autora nos turnos de trabalho manhã, tarde e noite, com a finalidade de apreender a organização do processo e do espaço de trabalho, as práticas de trabalho e suas dinâmicas, as interações entre os membros da equipe multiprofisisonal e o cotidiano do trabalho de enfermagem em emergência e urgência clínica.

Após a leitura exaustiva do conteúdo das entrevistas e da descrição das observações efetuadas foram identificados os núcleos de sentidos dos relatos emitidos e a seguir, codificados, organizados e analisados os dados tematicamente ${ }^{(14)}$.

\section{RESULTADOS}

No artigo ora apresentado é analisado a categoria empírica: o tempo no trabalho, evidenciando que na percepção dos trabalhadores de enfermagem o tempo é o presente e se manifesta como duração e como ritmo. Já na percepção dos usuários o tempo é o agora e se manifesta como possibilidade de alívio da dor, recuperação da saúde e manutenção da vida. Isto significa que o trabalhador, embora perceba e se empenhe para a realização das atividades de forma rápida, não 0 faz de acordo com o tempo esperado e requerido pelas necessidades dos usuários.

\subsection{Tempo Presente como Duração e como Ritmo}

Observou-se que no trabalho, o quadro temporal é marcado pelo tempo do relógio, pelo ritmo da demanda de usuários e pela jornada de trabalho. Além da exigência de pontualidade e regularidade, há também uma pressão para rapidez na realização das atividades, não só pela alta demanda, mas também pela necessidade de vencer a corrida em benefício da vida. 0 corpo do trabalhador precisa ajustar-se a rapidez pela necessidade do usuário e pelas exigências institucionais.

Nesse ajustamento do tempo às atividades assistenciais, cada trabalhador reage de forma singular: alguns adoram esse ritmo acelerado de fazer as coisas considerando o fator rapidez como prazer no trabalho.

(...) Essa adrenalina que rola aqui dentro oh... (mostra as veias) Faz uma falta!!! Faz uma falta!... Eu estou lá em casa, às vezes e as crianças estão brincando ou estão chorando... Eu estou tentando bagunçar com as crianças que nem eu faço aqui... (...) Que nossa!... É muito louco... Isso daqui é muito legal! Adoro! Adoro trabalhar aqui! (..) (Aram).

Neste relato pode-se considerar duas possibilidades na relação existente entre o contexto estressante do trabalho de emergência e seus efeitos na vida do profissional, quais sejam; os efeitos positivos para as pessoas que conseguem absorver o estresse laboral nas ações cotidianas e o efeito da organização científica do trabalho e os mecanismos de defesas protetores usados em resposta pelos trabalhadores.

Considera-se 0 efeito positivo de contextos estressantes para pessoas que gostam de ação e de vivenciar situações limites. Neste caso a pessoa situa-se em uma posição ativa em face das inúmeras fontes de estresse da vida profissional e 0 ambiente de trabalho tem um efeito benéfico. É o que parece acontecer com Aram, para o qual as características imprevisíveis, intempestivas e falta de controle se caracterizam como estímulos provenientes do trabalho em emergência clínica. A intensidade, a gravidade e as dificuldades da situação que podem ser insuportáveis para algumas pessoas, são vividas por ele de forma prazerosa, casos como esse são descritos na literatura(15).

Em segundo lugar, é preciso considerar que sendo o trabalho de emergência clínica condicionado à produtividade pela organização científica do trabalho a pessoa assume, o mesmo comportamento dentro ou fora do horário de trabalho. $\mathrm{O}$ ser humano como ser integral, sendo condicionado e despersonalizado no trabalho é também, igualmente, na sociedade. Desse modo, pode manter um ritmo acelerado em suas atividades diárias.

Essa situação é interpretada pela maioria dos autores como contaminação involuntária do tempo fora do local de trabalho. Considerase que o tempo fora do trabalho faz parte de um continuum do tempo da vida da pessoa, dificilmente dissociável. Neste caso, a aceleração do ritmo na realização das atividades fora do trabalho seria um esforço a adaptação de nova atividade repetitiva, cuja performance deva ser mantida. O ritmo do tempo fora do trabalho não é somente uma contaminação, mas, antes, uma estratégia que tem por finalidade manter eficaz a repressão dos comportamentos espontâneos que marcariam uma brecha no condicionamento produtivo(16).

Para outros trabalhadores que não têm como característica prazer pela ação e velocidade na realização de suas atividades, essa pressão do tempo exigindo aceleração no ritmo de realização das tarefas em uma situação em que os erros podem ser fatais, se manifesta como um fator desestabilizante, que gera cansaço e estresse que se refletem na vida doméstica.

(...) as vezes eu chego em casa com os nervos lá na ponta do... do... né? Eu falo pra minha esposa: olha, deixa-me ficar quietinho... e tomo um banho, né? E vou me deitar, não quero conversa com ninguém. (...) (Etê).

O tempo externo está relacionado à duração da jornada de trabalho 
e a delimitação da quantidade de tempo necessária a prestação das atividades nessa jornada. 0 tempo interno se relaciona com as características e a intensidade do trabalho inserido em determinada duração de tempo(11).

Isto significa que a mente do trabalhador está voltada, não só para o seu tempo de permanência no local de trabalho, mas também para sua quantidade disponível à realização das atividades assistenciais. Assim, o tempo se caracteriza como pressão psicológica no sentido de aceleração do ritmo de trabalho para conseguir atingir os objetivos assistenciais, dividindo sua atenção com todas as pessoas assistidas e os colegas da equipe de saúde.

Estudo realizado junto a categoria de enfermeiros sobre as diversas formas de utilização do tempo numa unidade de internação constatou que, além de suas atividades específicas, eles têm assumido outras que poderiam ser desenvolvidas pelos demais trabalhadores da equipe de saúde. Tais atividades se destinam em geral, a facilitação do serviço dos outros profissionais e não ao cumprimento de metas estabelecidas pela própria profissão. Assim, ao assumi-las, reduzem o tempo de trabalho em suas atuações especificas ${ }^{(17)}$.

$\mathrm{Na}$ unidade de emergência e urgência, também foi observada a utilização do tempo que deveria ser específico aos procedimentos da enfermagem para propiciar à toda equipe de saúde as condições necessárias ao salvamento da vida e à assistência ao doente. Assim, neste setor, o ritmo do trabalho é ditado pelas pela quantidade de usuários do serviço, pelo risco de vida e pelas condições de trabalho disponibilizadas para 0 atendimento. Além disto, a motivação para a aceleração do ritmo das atividades não se deve só à quantidade de usuários e a pressão dos administradores, mas também ao significado simbólico assumido pelos trabalhadores para este tipo de atividade, onde alguns minutos podem significar a morte.

Essa forma de percepção do tempo como duração, não surge espontaneamente para o trabalhador, mas é um modo de pensar direcionado pelas formas de organizações científicas do trabalho. Nessa perspectiva de entendimento do tempo, o trabalhador age em conformidade com 0 tempo "como um elemento-chave para a empresa" que, por meio de procedimentos racionais, maximiza o rendimento de trabalho ${ }^{(11)}$.

A temporalidade é vivida no contexto do trabalho estudado de forma característica onde a noção de atualidade, se constrói a partir da noção do tempo presente. 0 que é este tempo presente? 0 quê ele exige de cada um? Mesmo considerando que trabalhadores e usuários participam do momento presente, a percepção, a pressão psicológica e as exigências do tempo sobre cada um, acontecem de forma distinta. Há distinção entre o momento presente e o momento atual, ou entre "o hoje" e "o agora". Os trabalhadores se situam no hoje, enquanto os usuários se situam no agora.

O tempo percebido pelo trabalhador é o momento presente (o hoje), compreendido como um intervalo necessário para a tomada de decisões rápidas com a finalidade de manter ou salvar a vida humana. Neste sentido, eles sabem que é preciso manter a atenção constante e observar as pessoas sob seus cuidados, mas há necessidade de programar o tempo de atendimento, selecionando e priorizando os usuários a serem assistidos.

0 trabalhador procura direcionar suas atividades em ritmo acelerado se empenhando ao máximo para conseguir realizar suas atividades, mas por mais que intensifique seu ritmo de trabalho e mantenha sua cadência não consegue atender a alta demanda. Em algumas situações, é necessário o empreendimento de maior velocidade na realização das tarefas se situando no tempo atual (o agora). Isso acontece nos casos de parada cárdio- respiratória como refere a trabalhadora:

(...) Então é tipo assim: você sabe... ah... é engraçado, como um pede daqui e outro pede dali, pede dali... Ai quando um diz: Ah, aquele paciente parou!!!... Vamos correr agora!!! É emergente! (Naurú).
0 trabalhador tem consciência de que muitas atividades não foram realizadas, porque sua capacidade de atendimento não foi suficiente para atender a demanda, mesmo aumentando o seu ritmo de trabalho. Assim, a pressão do tempo se torna uma constante nas suas ações cotidianas, gerando no trabalhador pressa e a sensação de impotência.

Essa pressão constante do tempo participa na gênese da violência, pois o trabalhador ao realizar atividades apressadamente pode cometer imperícias e negligências e com isto desencadear reações violentas nos usuários, como demonstra o relato a seguir:

(...) É o que eu falei pra você: ali são muitas pessoas para serem atendidas e não dá tempo. Porque quando chega, você vê que chega bastante pessoas com AVC'.... Outros com parada, ou até duas paradas seguidas, né?. Etem pessoas de todo tipo, né? Então... muitas vezes, aquela espera das pessoas ali na porta as irritam (...) (Etê).

Mesmo consciente de que deveria desempenhar com qualidade as atividades para as quais está habilitado, o trabalhador não consegue realizá-las de forma satisfatória. Esse reconhecimento, mesmo sendo justificado pelo excesso de trabalho, não diminui sua sensação de impotência e culpa pela baixa qualidade da assistência prestada.

A pressão do tempo se torna mais intensa pelos conflitos que se estabelecem entre os usuários e os demais membros da equipe de saúde, como mostra o relato a seguir.

\begin{abstract}
(...) Você sabe que o setor ali não dá de você ficar de hora em hora em cima de certos pacientes, né? Você os olha, mas não dá para ficar... Então, às vezes eles (os médicos) ficam assim: instigando os pacientes a cobrar da enfermagem alguns procedimentos, que teria que a enfermagem realmente fazer, só que pelo número de funcionários não dá... Não consegue! Aí o quê é que fica? Fica aqueles acompanhantes ali... sabe? De olho na enfermagem! Ai toda hora eles (cobram): você não fez!!! Você não fez! Você está menosprezado a minha mãe, ou o meu pai? (...) Como se você não quisesse fazer. Como se eles fossem... Tipo um guarda, né? Um vigia do funcionário de enfermagem (...) (laê).
\end{abstract}

O tempo percebido pelo trabalhador como o momento presente, faz com que ele organize suas atividades direcionando-as às doenças e à probabilidade de morte. Nesse tempo, ele conduz suas atividades de forma assistemática ou seja, executa ações que considera prioritárias dentro do que constitui os problemas rotineiros do atendimento, mas com a observação voltada para abandoná-las a qualquer momento e dedicar-se integralmente às situações de emergência que o situa "no agora".

(...) Ela (a pessoa usuária) aguarda o atendimento, mas como sempre é dada prioridade para quem precisa de atendimento de mais urgência, né? Aí, muitas vezes a pessoa se sente constrangida, porque outra pessoa é passada para frente e às vezes ela acha que está sendo excluída por parte do atendimento. Mas é que nós damos prioridade para quem precisa mesmo de atendimentos... Os pacientes mais graves.... (...) (Toriba).

Dessa forma, a sobrecarga de trabalho leva o trabalhador a experimentar cotidianamente o dilema ético, de ter que optar entre dois ou mais atendimentos, igualmente necessários, e acaba naturalizando esta situação e justificando sua opção como uma decisão naturalmente lógica que deveria ser compreendida pelos usuários e pelos seus familiares, como narrado a seguir:

(...) Não que elas (as pessoas doentes) não precisem de cuidados, 
elas precisam. Só que elas têm que entender que quando a gente está naquela correria não é porque a gente não quer atender a elas... a necessidade do outro que está ali perto delas é maior do que a delas (...). Então, muitas vezes, a gente tem que... Às vezes, deixar de atender um que tá mais ou menos para atender outra pessoa que está com um problema maior, né? Com uma dor... Muitos não entendem isso... (Etê).

Entendendo culturalmente o tempo de forma linear, o trabalhador atua como elemento na constituição da violência no contexto hospitalar e colabora para sua perpetração. Assim, atos de violências são praticados inconscientemente, pois o trabalhador incorporou estas situações como parte 'normal' do atendimento de emergência e urgência clínica. Assim, a violência se forma na própria dinâmica do atendimento, ou seja, como a quantidade de trabalhadores é insuficiente para 0 atendimento das demandas de trabalho, as prioridades são definidas no momento em que todos aguardam na fila esperando ansiosos pelo atendimento. $O$ relado descrito a seguir evidencia como são determinadas as prioridades no serviço de emergência e urgência.

(...) É pelo andar, né? Pela avaliação que fazemos, muitas vezes, diante da fila, né? Que chegou o caso de eu ver um paciente infartado aguardando na fila, tive que tirar uma paciente com problema de DNV diante do consultório, para dar prioridade para o que estava infartando.. (...) (Toriba).

Mesmo considerando que existem situações que exigem atuação imediata pelos profissionais da saúde, esse critério não pode ser usado como uma forma rotineira de atendimento, pois todas as pessoas que procuram os serviços de emergência clínica precisam de avaliação e tratamento adequados para a resolução de seus problemas de saúde.

Os dados mostram que a organização do trabalho na unidade estudada, evidenciada pelo número insuficiente de profissionais de enfermagem, está em desacordo com as instruções normativas do Ministério da Saúde e do Conselho Federal de Enfermagem, que preconizam a quantidade suficiente de enfermeiros, técnicos e auxiliares para o atendimento dos serviços de emergência e urgência nas 24 horas do dia(18,19).

Outro aspecto a ser considerado na análise da equalização do tempo de trabalho é a forma utilizada para garantir a organização do processo de trabalho e a delimitação do tempo destinado a cada tarefa. A disciplina como técnica de controle instituicional tem sido um dos modos de manifestação de violência nos locais de trabalho, muitas vezes imperceptível aos olhos dos trabalhadores. A disciplina é uma espécie de contra-direito, conforme descrito a seguir: "as disciplinas têm o papel preciso de introduzir assimetrias insuperáveis e de excluir reciprocidades. Em primeiro lugar porque a disciplina cria entre os indivíduos um laço 'privado', que é uma relação de limitações inteiramente diferente da obrigação contratual; a aceitação de uma disciplina pode ser subscrita por meio de contrato; a maneira como ela é imposta, os mecanismos que faz funcionar, a subordinação não reversível de uns em relação aos outros, o 'mais-poder' que é sempre fixado do mesmo lado, a desigualdade de posição dos diversos 'parceiros' em relação ao regulamento comum opõem o laço disciplinar e 0 laço contratual, e permitem sistematicamente falsear este último a partir do momento em que tem por conteúdo um mecanismo de disciplina"(20).

Pela caracterização da disciplina descrita e observando-a em várias situações no hospital, pode-se afirmar que sua prática constitui-se em uma forma de violência. Os termos e as expressões como: "assimetria", "exclusão de reciprocidades", "relação de limitações", "aceitação", "imposição", "subordinação", "mais-poder...", reportam a sentimentos de violência. Desse modo, sua inserção no processo produtivo, constitui em um dos modos de gerir o tempo sobre a vida das pessoas, de forma que o tempo seja amplamente utilizado(20).
Assim, a pressão do tempo mecânico das horas, age como modalidade do controle que coage o corpo continuamente em relação às atividades que deve realizar mais do que sobre 0 efeito das mesmas e, é exercida por meio de códigos que pormenoriza ao máximo o tempo, o espaço e os movimentos.

A disciplina atuante sobre o corpo do trabalhador se dá no sentido material da carga excessiva de trabalho, mas a motivação para a sua prática se faz por vias emocionais, ou seja, os clientes precisam que sua atuação seja eficiente e o colega da equipe seguinte "merece" seu esforço para que não receba o trabalho acumulado.

(...) uma das coisas que revoltam também... Chega até ser assim: tipo assim, massacrante. Porque... Vê se você me entende? A gente chega as sete... nós temos um horário a cumprir... chegar às 7 horas é sagrado, tem que ser fiel. Chegar 7 horas em ponto. Nessas 7 horas, independente do volume... Independente da quantidade... Se tá calmo... Se tá agitado... Nessas 7 horas a gente tem aquela carga horária para cumprir. (...) (Aram).

As disciplinas se tornaram, nos séculos XVII e XVIII, fórmulas gerais de dominação. Elas dizem respeito a uma arte do corpo humano para 0 aumento de suas habilidades e para formação de um mecanismo que 0 torne mais obediente e útil. Elas fabricam corpos pacíficos, ou seja, corpos de fácil condução e adestramento. Corpos que não se opõem a serem guiados. Elas aumentam as forças do corpo no sentido de produzir mais, trabalhar mais e diminui suas forças no sentido da reação, ou de contrapor àquilo que o coage. Aumentam também, a aptidão do corpo e, ao mesmo tempo, 0 impedem de agir livremente ${ }^{(20)}$.

(...) Eu não faço mais porque é... Muitas vezes a gente não tem aquela força, né? (...) (Etê).

(...) Embora a gente seja preocupada com o paciente, mas sempre a gente acha que teria que ser feito alguma coisa a mais no plantão e que a gente deixou de fazer e isso é uma sensação ruim. (...) (Naurú).

A disciplina como técnica de sujeição atua pelo controle da atividade. A princípio, esse controle atua sobre o horário, visando a utilização máxima do tempo, ou impedindo o seu desperdício. Essa atuação ocorre por meio de três grandes processos: "estabelecer cesuras, obrigar as ocupações determinadas, regulamentar os ciclos de repetição". Esses processos, por sua vez, implicam: tempo, ritmo e regularidades; tempo integralmente útil é tempo medido e pago, deve ser um tempo limpo, de boa qualidade e que no seu decorrer, o corpo seja movimentado e exercitado ${ }^{(20)}$.

Em segundo lugar, controle da atividade atua sobre "a elaboração temporal do ato". O corpo deve ser ajustado aos imperativos temporais. Estabelece-se um quadro geral para uma atividade. Implica um programa. "O tempo penetra o corpo, e com ele todos os controles minuciosos do poder". Esse controle rigoroso sobre o corpo produtivo leva o trabalhador a sentir-se como eterno devedor de suas tarefas, como expressado a seguir ${ }^{(20)}$ :

[...] é você ter sempre a impressão de que alguma coisa que era pra ser feita deixou de fazer. Você não conseguiu concluir... As vezes uma pressão que você deixou de olhar de um paciente que estava hipertenso... aquilo lá, você sai do plantão, né? Pô!... e se ele piorar? (...) (Nauru).

Em terceiro lugar, o controle da atividade imprime ao corpo e aos gestos pontos de correlação. Implica um controle disciplinar que, além 
de ensinar, ou impor uma série de gestos definidos, também impõe uma relação entre um gesto e a atitude global do corpo. Promove a condição de eficácia e rapidez: nada deve ficar ocioso ou inútil, tudo deve dar suporte ao ato requerido. 0 gesto eficiente tem por base 0 corpo disciplinado(20).

Em quarto lugar, o controle sobre a atividade se dá pela "articulação corpo-objeto: a disciplina define cada uma das relações que o corpo deve manter com o objeto que manipula. Ela estabelece cuidadosa engrenagem entre um e o outro". Estabelece-se, uma codificação instrumental do corpo $^{(20)}$.

Em quinto lugar, o controle da atividade atua pela utilização exaustiva. Trata-se da utilização crescente do tempo "extrair do tempo sempre mais instantes disponíveis e de cada instante sempre mais forças úteis". O controle da atividade como técnica disciplinar é sentido pelos trabalhadores, sendo expresso da seguinte forma ${ }^{(20)}$

(...) Eu acho que é um massacre porque você trabalha ali, praticamente as 12 horas noturnas, tem noite a gente não consegue repousar. Fica todo mundo direto naquele pronto atendimento. E... essa carga horária de trabalhar a noite, ir para casa dia... que entre aspas, na verdade ele não vai para casa mas para um outro serviço (...) e trabalha muito! Porque aqueles meninos(auxiliares e técnicos) trabalham...(Nunguara).

Essa técnica de controle do trabalho implica uma intensificação do uso do tempo. Busca unir ao máximo de rapidez o máximo de eficiência. Tem como lógica que quanto mais o tempo se decompõe, mais acelerada é a operação, ou, pelo menos, mais regulável de acordo com um rendimento ótimo de velocidade. Para isso é necessário regular o tempo de ação. Por meio dessas técnicas de sujeição vai se constituindo, lentamente, um novo objeto que substitui o corpo mecânico: o corpo natural possuidor de forças e sede de algo durável $\left.\right|^{(20)}$.

A lógica que direciona a conduta dos trabalhadores em relação a sua percepção do tempo no trabalho, tem como base a sua concepção sobre doença, morte e os meios de que dispõe para evitá-las.

Outra percepção do tempo é utilizada pelos usuários do sistema público de saúde, que buscam o atendimento de emergência e urgência clínica, e essa percepção se confronta com a lógica de tempo do trabalhador de enfermagem e é percebida por eles.

\subsection{O Tempo "Agora" como Possibilidade de Alívio da Dor, Recuperação da Saúde e Manutenção da Vida}

A concepção de tempo para os usuários tem como lógica dominante: a possibilidade de alívio da dor, do sofrimento e do medo da morte. A dimensão temporal é, para eles, o agora.

Os usuários do sistema público de saúde e seus familiares ao procurarem o pronto atendimento esperam ser atendidos, pronta e imediatamente, pois estão tensos devido aos seus problemas de saúde. Quando esse atendimento não se faz na tolerância de tempo por eles definidos como adequados, iniciam-se manifestações de diversas formas de violência. Esta concepção de um tempo imediato do doente e seus familiares não passa desapercebida pelos trabalhadores de enfermagem que se manifestam da seguinte forma:

(...) porque a partir do momento que o usuário chega aqui e ele precisa do serviço, pra ele o problema dele é importante e ele quer uma solução. Então, ele não vai aceitar chegar ali e voltar para casa. (...) (Yamí).

Associado à dor e ao temor da morte, outros fatores colaboram para que os usuários concebam o tempo presente como o agora e exijam um atendimento imediato, destacando-se dentre eles: a) 0 conceito de pronto socorro como um espaço do sistema de saúde capaz de oferecer um atendimento rápido e eficiente; b) a informação por parte dos meios de comunicação de que a saúde é um direito do cidadão, sem uma orientação mais clara e específica sobre os canais que devem ser usados para essa reivindicação e sobre o fluxo de atendimento da rede básica e hospitalar estruturado em níveis de complexidade e regionalização; c) a incitação dos usuários por parte de alguns médicos, quanto a exigência da realização imediata da prescrição médica.

Esses fatores, associados ao espaço físico inadequado para a realização das atividades assistenciais, dimensionamento insuficiente do quadro de profissionais de enfermagem e organização precária do processo de trabalho, propiciam tensões gerando conflitos que se manifestam de forma intensa e estressante sobre os trabalhadores de enfermagem, como pode-se observar no relato:

(...) Essa coisa de está pondo o paciente ou o próprio acompanhante cobrando da enfermagem é... Procedimentos... Cuidados, né? (...) "porque tem que olhar a pressão, porque o médico falou que tem que tá olhando... é 10 horas? 10 e meia?"- Eles têm que tá lá olhando. - E ainda define hora, entende? (...)" (laê).

O trabalhador se vê triplamente pressionado pelo tempo: o tempo de ação exigido por eles mesmos, o tempo como uma determinação social e de cidadania e, o tempo requerido pela necessidade biológica da prescrição médica.

Essa exigência de atuação imediata, sem a devida infra-estrutura para um atendimento de qualidade, leva o trabalhador a atuar com pressa. Esse atendimento apressado está na gênese de algumas manifestações violentas nesse contexto de trabalho: a) as omissões de violências presenciadas, mas não denunciadas por falta de tempo, (tempo para: diálogo, fazer comunicações internas ou denúncias); b) as negligências devido a cuidados deixados para depois e que acabam sendo esquecidos, porque, a todo o momento, novos atendimentos precisam ser priorizados; c) informações e orientações fragmentadas, ou negadas. Enfim, a banalização de várias manifestações de violências, pois mesmo quando observadas, pouco ou nada é feito para seu enfrentamento e contenção.

\section{CONSIDERAÇÕES FINAIS}

O tempo insuficiente para a execução das atividades de enfermagem em situações de urgência e emergência mostrou-se ser uma das causas que impulsiona a manifestação de diferentes formas de violência no local de trabalho: "a violência estrutural" das condições precárias de trabalho e da quantidade insuficiente de trabalhadores para a realização com qualidade do trabalho de enfermagem levando a sobrecarga física e mental; a "violência clássica" como agressão física ou verbal de colegas da equipe multiprofissional e da clientela; a "violência repressiva" como a negação do direito de exercer com segurança as atividades assistenciais e a um ambiente de trabalho seguro; e a "alienação" manifestada no empecilho de usufruir o prazer de uma realização competente e eficaz e de ser valorizados socialmente junto a clientela ${ }^{(21)}$.

O tempo é tão importante para a realização das atividades assistenciais, que o Conselho Nacional de Enfermagem no Brasil (COFEN) estabeleceu na Resolução 293/2004 um parâmetro de tempo como subsídio para fixação e dimensionamento do quadro de pessoal de enfermagem nas instituições de saúde no Brasi|(22). A Resolução CONFEN $272 / 2002^{(23)}$, diretrizes para a sistematização da assistência de enfermagem, como parte da organização de seu processo de trabalho, o que auxilia no planejamento do emprego do tempo de trabalho diante das demandas apresentadas.

As organizações de saúde devem estabelecer políticas formais e atitudes administrativas propiciadoras de um ambiente de trabalho 
seguro e implementar estratégias para inibir qualquer forma de violência no local de trabalho. Essa posição deve ser reforçada por políticas claras e definições documentadas de procedimentos em relação à violência ${ }^{2}$

Uma cultura do local de trabalho, centrada na pessoa, que tenha por base a dignidade, a não discriminação, a igualdade de oportunidades e a cooperação, incluindo iniciativas de sensibilização quanto ao problema da violência em todos os âmbitos, é uma das recomendações da OIT para a minimização da violência nos locais de trabalho ${ }^{(23)}$. Neste sentido, uma quantidade suficiente de tempo destinado a realização das atividades assistenciais se torna imprescindível.

\section{REFERÊNCIAS}

1. Di Martino V. Workplace violence in the health sector - country case studies (Brazil, Bulgaria, Lebanon, Portugal, South Africa, Thailand, and an additional Australian study): synthesis report. Genebra (SWZ): OIT/OMS/CIE/ISP; 2002

2. Consejo Internacional de Enfermeras. Directrices para hacer frente a la violencia en el lugar de trabajo. Genebra (SWZ): CIE; 1998.

3. Sullivan EJ. Violence and Nursing. J Prof Nurs 1999 sep-oct; 15(5): 259-60.

4. Hirigoyen MF. Mal-estar no trabalho: redefinindo 0 assédio moral. Rio de Janeiro (RJ): Bertrand Brasil; 2002.

5. Alaim J. Introducción general. In: Joxe A. La violencia y sus causas. Organización de las Naciones Unidas para la Educación, la Ciencia y la Cultura 7. Paris (FRA): UNESCO; 1981.

6. Domenach JM. La violencia. In: Joxe A. La violencia y sus causas. Organización de las Naciones Unidas para la Educación, la Ciencia y la Cultura 7. Paris (FRA): UNESCO; 1981

7. Rosso SD, Freitas CES. A violência na história brasileira do trabalho. In: Silva LDR. Violência e trabalho no Brasil. Goiânia (GO): Editora da UFG; 2001. p. 31-48.

8. Brasil. Jornal Segurança e Saúde no Trabalho. Mundo do trabalho: banco de dados estimulará prevenção de acidentes de trabalho. [citado em: 12 dez 2004]. Disponível em: URL: www.dnamicsite.com.br

9. Brasil. Ministério da Saúde. Departamento de ações programáticas estratégicas. Área técnica de Saúde do Trabalhador. Cadernos de saúde do trabalhador: legislação. Elaboração e organização: Letícia Coelho da Costa. Brasília (DF): Ministério da Saúde; 2001.

10. Gasparinil G. Tempo e trabalho no ocidente. In: Chanlat J-F. Coordenador. O indivíduo na organização: dimensões esquecidas v. 3, São Paulo: Atlas, 1996. p.175-193.

11. Hassard J. Tempo de trabalho: outra dimensão esquecida nas organizações. In: Chanlat JF, coordenador. O indivíduo na organização: dimensões esquecidas. Vol. 1. $3^{\mathrm{a}}$ ed. São Paulo (SP): Atlas; 1996. p. 175-193.

12. Marx K. O capital: crítica da economia política. $3^{\mathrm{a}}$ ed. São Paulo
(SP): Nova Cultural; 1998.

13. Pires D. Reestruturação produtiva e trabalho em saúde no Brasil. São Paulo (SP): CUT - Anablume; 1998.

14. Bardin L. Análise de conteúdo. Lisboa (POR): Edições 70; 1977.

15. Aubert N. A neurose profissional. In: Chanlat JF, coordenador. $O$ indivíduo na organização: dimensões esquecidas. Vol. 2. $3^{\mathrm{a}}$ ed. São Paulo (SP): Atlas, 1996.

16. Dejours C. A loucura do trabalho: estudo de psicopatologia do trabalho. $5^{\text {a }}$ ed. ampliada. São Paulo (SP): Oboré; 1992

17. Lunardi VL, Lunardi Filho WD, Borba MR. Como o enfermeiro utiliza o tempo de trabalho numa unidade de internação. Rev Bras Enferm 1994 jan-mar; 47(1): 7-14.

18. Brasil. Ministério da Saúde. Política nacional de atenção as urgências. Brasilia (DF): Ministério da Saúde; 2004.

19. Brasil. Resolução COFEN n $293 / 2004$. de 21 de Setembro de 2004 . Fixa e estabelece parâmetros para o dimensionamento do quadro de profissionais de enfermagem nas unidades assistenciais das instituições de saúde e assemelhadas. [citado em 18 dez 2004]. Disponível em: URL: http:/www.portalconfen.com.Br/section_int.asp? infolD=3836\&EditionSection $I D=11$ \&

20. Foucault M. Vigiar e punir: história da violência nas prisões. $13^{\mathrm{a}} \mathrm{ed}$. Petrópolis (RJ): Vozes; 1996.

21. Galtung J. Contribuición específica de la irenología al estudio de la violencia: tipologias. La violencia. In: Joxe A. La violencia y sus causas. Organización de las Naciones Unidas para la Educación, la Ciencia y la Cultura 7. Paris (FRA): UNESCO; 1981

22. Brasil. Resolução COFEN n 272/2002. De 27 de Agosto de 2002. Dispõe sobre a sistematização da assistência de enfermagem nas instituições de saúde brasileiras.[citado em: 18 dez 2004]. Disponível em: http:/www.portalconfen.com.br/section_int.asp?infolD= 3836\&EditionSection $\mid \mathrm{D}=11$ \&se

23. Conselho Internacional dos Enfermeiros (ICN). Violência: uma epidemia. [citado em: 15 nov 2004]. Disponível em: http://www.icn.ch/ matters 